\title{
Experience in treatment of comorbid pathologies in calves in the neonatal period
}

\author{
Pavel Parshin ${ }^{1}$, Dmitry Savrasov ${ }^{2 *}$, and Vasiliy Dorozhkin ${ }^{3}$ \\ ${ }^{1}$ All-Russian Veterinary Research Institute of Pathology, Pharmacology and Therapy, 394087 Voronezh, Russia \\ ${ }^{2}$ Voronezh State Agrarian University named after Emperor Peter the Great, 394087 Voronezh, Russia \\ ${ }^{3}$ All-Russian Research Institute of Veterinary Sanitation, Hygiene and Ecology - branch of Federal Scientific Centre - All-Russian \\ Research Institute of Experimental Veterinary Medicine of the Russian Academy of Research, Moscow, Russia
}

\begin{abstract}
The article describes an integrated approach in the treatment of hypotrophic calves with transindromal comorbid anemia. The clinical status of the calves was established and the therapeutic effect of the combined use of Carnitine chloride, Actovegin and Taurine on the metabolic status of calves with comorbid diseases in the neonatal period, restoration of hematopoiesis, energy status and reduction of imbalance of immunological parameters was studied. As a result, a decrease in the sensitivity of young animals to adverse environmental factors was found.
\end{abstract}

\section{Introduction}

The use of the production potential of dairy cattle breeding largely determines the efficiency of the economy of farms. The competitiveness of livestock breeding is laid during the period of receiving and raising calves, it is determined by their viability, health, growth, development, bioconversion of feed, maintenance and treatment. Growing young animals should be organized in such a way as to ensure normal growth, development and lay the foundation for the manifestation of genetically based productive capabilities of animals at low labor costs and optimal feed consumption [1-4]. One of the most critical periods of ontogenesis is the first month of life is the neonatal period. This period is characterized by the greatest tension of metabolic processes, the greatest danger of failure of adaptive mechanisms in the face of a sharp change in the environment (the transition from intrauterine to extrauterine). Therefore, the concept of the health of a newborn includes the concept of its optimal adaptation to changing environmental conditions and the evaluation of the results of adaptation mechanisms in the near (first month of life) and distant (subsequent life) perspective.

The intensification of animal husbandry, oriented mainly at increasing productivity without taking into account changes in the needs of the body, first leads to an increase in the sensitivity of animals to adverse environmental factors, and then to immunometabolic disorders and the development of the disease.

For modern veterinary medicine, forecasting the state of calves' health is of urge, since it allows identifying among them the risk groups for the development of certain diseases, and most importantly, to carry out preventive and therapeutic measures in a timely manner.
The birth of a calf is accompanied by a single functional system of the mother-placenta-fetus, the launch of a system of adaptive mechanisms formed during the period of intrauterine development. The preservation of the vital activity of the newborn and the subsequent process of establishing the functions of organs and systems of the body depend on the usefulness of the metabolic adaptation that occurs during the first minutes or hours of life.

After the birth of a calf, its own mechanisms of metabolic regulation are turned on, and, first of all, the problem of energy supply of homeostasis of the newborn due to its own (endogenous) energy sources arises. The organism of newborns has high manageability and it is most advisable to form its resistance and adaptive abilities in the early stages of ontogenesis. If the conditions of keeping, feeding and caring do not meet the requirements of the organism, animals are forced to adapt to these conditions, primarily due to increased energy costs.

Metabolic processes are impaired, calves's health is deteriorating, resistance is decreasing, which ultimately leads to the development of gastrointestinal diseases. This is especially true for newborn calves, which are little adapted to protection from adverse environmental factors. In addition, the development of the animal in the early stages of life largely determines the continued successful rearing of replacement and feeder young animals.

Therefore, the stimulation and strengthening of the body's natural defenses, their long-term maintenance at a high level is the most important task of livestock breeders. Among the diseases characterized by metabolic disorders, a special place is occupied by malnutrition and anemia of young animals. Hypotrophy is the pathology of the fetus, manifested by a violation (deterrence,

* Corresponding author: mitrij-savrasov@yandex.ru 
inhibition) of its development and arising as a pathophysiological reaction to an insufficient supply of oxygen to the fetus, nutrients and biological active substances, or in violation of their digestibility. Hypotrophy reflects the concept of "physiological immaturity" of newborns.

This pathology causes significant economic damage to farms, which is characterized by a reduction in the useful life, loss of body weight, death and forced culling of animals, loss of breeding qualities, deterioration in the quality of animal meat and a decrease in the return on feed. In newborn hypothrophic calves, redox processes are disturbed and oxygen starvation of tissues develops. Under-oxidized products of the intermediate metabolism enter the bloodstream, causing trophic disorders of various organs and systems, peripheral vascular spasms, and tachycardia. Congenital malnutrition in calves is accompanied by the development of secondary immune deficiency, which exacerbates age-related immune deficiency. A decrease in immune reactivity, in turn, inhibits erythropoiesis, exacerbating the course of malnutrition [2, 3, 5-21].

Hypochromic microcytic anemia (GMA) is a disease that is characterized by impaired hemoglobin synthesis due to iron deficiency. The disease is caused by a lack of iron in the body, accompanied by a violation of the function of the blood-forming organs, a decrease in the formation of red blood cells, a low hemoglobin content, a metabolic disorder leading to growth retardation and a decrease in body resistance. Latent iron deficiency is one of the most common nutritionally dependent conditions in young farm animals.

This is due to the increased need for a newborn organism in iron during periods of intensive growth. In addition, iron deficiency states develop under the influence of such unfavorable factors as low body weight at birth, as well as nutritional reasons: an unbalanced diet, early feeding by non-adapted substitutes, early introduction of roughage into the diet. It has been established that a significant role in the occurrence of iron deficiency in young calves is played by increased iron loss as a result of diapedetic microblood loss through the intestine. The significance of each of the listed causes of iron deficiency anemia varies depending on the age period [1, 3, 22, 23].

A comorbid disease profile with multisystem multiple organ failure is one of the most dangerous risks of disturbance in the harmonious modeling of the organism of young farm animals, the likelihood of which increases with a decrease in technology adaptability [4, $24,25]$.

The aim of our research is to develop a new comprehensive treatment regimen for comorbid hypotrophy and anemia in newborn calves, based on the use of modern medicines.

\section{Materials and methods}

Scientific production experiments were carried out in the Voronezh region at livestock breeding complexes of dairy cattle breeding, with a total livestock of 2.5 thousand. The material for the study were calves from the Holstein-Friesian breed aged from birth to 14 days. For the experiment, 3 groups of calves were formed. Calves with signs of moderate prenatal malnutrition were divided into 2 groups: control (intact) and experimental with 6 animals each, all calves had similar age, body weight and were in the same conditions of keeping, feeding and care. The group of clinically healthy calves was also formed to evaluate reference values. Newborn calves with acute infectious inflammatory diseases were excluded from the study group. After calving, all calves were placed in an individual box with an infrared irradiator. On the second day of life they were transferred to an individual pen. In order to restore metabolic status of animals from an experimental group, from the first day of life, in a mixture with $200 \mathrm{ml}$ of Ringer-Locke solution, $10 \%$ carnitine chloride solution was administered intravenously once at a dose of $100 \mathrm{mg} / \mathrm{kg}$ for 7 days; Actovegin at a dose of $5 \mathrm{mg} / \mathrm{kg}$ was used to stimulate erythropoietic function of the red bone marrow and increase the reactivity of the body; once a day for 10 days during the first 14 days of their life, Taurine at a dose of $100 \mathrm{mg} /$ animal was administered orally together with colostrum and milk to prevent stressful maladaptation.

Carnitine is a vitamin-like compound derived from an amino acid that allows the transfer of fatty acids across mitochondrial membranes, thereby improving their availability for beta oxidation and trapping potentially toxic organic compounds. Carnitine is a transmembrane carrier of fatty acids [26].

Actovegin ${ }^{\circledR}$ is an antihypoxant. It is a hemoderivative, which is obtained through dialysis and ultrafiltration. It has a positive effect on the transport and utilization of glucose, stimulates oxygen consumption (which leads to stabilization of the plasma membranes of cells during ischemia and a decrease in the formation of lactates), thus having an antihypoxic effect. It increases the concentrations of adenosine triphosphate, adenosine diphosphate, phosphocreatine, and also the amino acids glutamate, aspartate, and gamma-aminobutyric acid [27].

Taurine (2-aminoethanesulfonic acid) is the end product of the exchange of amino acids containing sulfur (methionine, cysteine, homocysteine, cystine). The key role in the synthesis of taurine in animals is played by the enzyme cysteine sulfinate decarboxylase. In most cases, taurine is described as the main osmoregulator of the cell, a membrane protector, an intracellular calcium regulator, which has the properties of an antioxidant, a detoxifier, which is involved in the metabolism of fats and fat-soluble vitamins, and affects inflammatory processes [28, 29].

The results were taken into account on 7-9th and on 12-14th days of the experiment. The calves of the control group were not treated. The first portion of colostrum was drunk by force with the help of a drencher. Given the small volume and underdevelopment of the gastrointestinal tract, colostrum was fed in a reduced volume: 3 liters (normal volume is 4 liters). To achieve the optimal amount of immunoglobulin and the formation of passive immunity, colostrum of the first 
milk yield was fed from cows of $2-3$ periods of lactation with a relative density of $1.067-1.068 \mathrm{~g} / \mathrm{cm}^{3}$, which was determined using a colostrometer. Frozen colostrum was stored in the "bank". Before taking the blood, a clinical examination of the calves was carried out, according to the generally accepted method. Blood was taken from the studied newborn calves for morphological and biochemical analysis from the jugular vein (venae jugulares) in the morning before the first colostrum drink and on the following days of research in the morning before feeding the animals. Laboratory analyzes were performed at the Department of Therapy and Pharmacologists of the FSBEI HE Voronezh State Agrarian University and the All-Russian Research Veterinary Institute for Pathology, Pharmacology and Therapy. Clinical studies of newborn calves were performed according to the plan generally accepted in veterinary medicine. In the blood, the number of red blood cells, white blood cells, hemoglobin, hematocrit was determined using an ABX Micros 60 hematology analyzer. The determination of TIBC, glucose, alkaline phosphatase, cholesterol, triglycerides was carried out by the chemical method using diagnostic kits on a PE$5300 \mathrm{~V}$ spectrophotometer. The content of inorganic phosphorus, iron and copper were determined on an Perkin Elmer 703 atomic absorption spectrophotometer. The bactericidal (SBA) and lysozyme (SLA) activity of blood serum, T- and B-lymphocytes, were determined in accordance with the "Methodological recommendations for the assessment and correction of non-specific resistance of animals" [25].

\section{Results and discussion}

According to the results, an attempt to stand independently in newborn hypotrophic calves was noted after 4-6 hours, the sucking reflex appeared after 3-4 hours, the sucking movements per minute were 77.0 \pm 3.0 . The response to a pinch determined a decrease in pain and tactile sensitivity; the lability of the nervous system was noted (sometimes apathetic, then excited). Milk teeth in some cases were underdeveloped. The mucous membranes were mostly anemic. The eyeballs are often sunken. Auricles and tail more noticeably drooping.

The body weight of hypotrophic calves was $30.8 \pm 0.4$ $\mathrm{kg}$, height at the withers was $67.9 \pm 0.7 \mathrm{~cm}$, chest circumference behind the shoulder blades was $74.0 \pm 1.3$ $\mathrm{cm}$, oblique body length $(\mathrm{cm})$ hypotrophic calves was $63.5 \pm 0.9$. The body temperature in newborn calves with antenatal hypotrophy was $38.1 \pm 0.4$. The number of heart contractions per minute was $129.5 \pm 2.6$, the number of respiratory movements per minute was $61.5 \pm 1.8$. Hypotrophic calves had reduced skin turgor, the hairline was tousled, dull, but dense and strong. The hairline in newborn calves with this pathology was disheveled, dull and there were areas of alopecia. The subcutaneous fat layer was initially thinned on the abdomen and in other parts of the body. Meconium was unformed, yellow with a greenish tint.
The presence of bilirubin in feces was established, which was also confirmed by a test for bile pigments. Microscopic examination of the feces of newborns revealed amylorrhea and steatarea, neutral fats (++++) were detected.

According to the results of laboratory studies, by the seventh day, calves of the experimental group demonstrated an increase in the number of red blood cells by $14.7 \%$, hemoglobin by $33.6 \%$. An increase in the studied indicators of micromineral metabolism was recorded, so the serum iron increased by $29.9 \%$, the copper level became higher by $22.1 \%$.

However, the indicators of the microelement composition of the blood we studied were within the lower limit of the norm. In calves of the control group, an increase in these indicators was also noted, but it was insignificant and did not reach physiological parameters. The hematocrit level corresponded to the values of the course of anemia in the studied animals. By the fourteenth day of studies in calves of the experimental group, the studied parameters returned to optimal values, so the number of red blood cells and hemoglobin increased by $28.3 \%$ and $61.1 \%$, respectively. The level of iron in serum became higher by $57.4 \%$, and copper by $38.6 \%$.

The correlation of data, research results before and after the experiment showed a decrease in the total ironbinding ability of blood serum by the seventh day by $10.2 \%$, and by the fourteenth day from the start of the study, its level decreased by $13.8 \%$ and began to correspond to the norm. Hematocrit in experimental calves recovered to physiological values. In calves of the control group, by the fourteenth day of the experiment, the studied hematomorphological parameters did not reach reference values.

The cell immunity in patients with congenital malnutrition of the calves of the experimental group, after the treatment we used, contributed to an increase in the number of leukocytes by $6.6 \%$, which corresponded to the physiological trend. The content of $\mathrm{T}$ - and $\mathrm{B}$ lymphocytes increased by $72.7 \%$ and $80.0 \%$, respectively. Indicators of the humoral link: SBA reached the norm by the end of the studies due to an increase of $46.4 \%$, SLA decreased by $38.5 \%$. On the fourteenth day of the experiment, in the animals of the control group, SBA did not change significantly, and SLA decreased 2.7 times, which did not correspond to the reference values.

By the fourteenth day, the amount of glucose in blood in newborn calves of the experimental group increased by $43.8 \%(\mathrm{P} \leq 0.05)$, but this value did not exceed physiological values, and in calves of the control group this indicator increased by $7.3 \%(\mathrm{P} \leq 0.05)$ on the seventh day of life and by $9.9 \%$ on the fourteenth day. The content of inorganic phosphorus in animals of the experimental group increased by $15.1(\mathrm{P}<0.01)$ by the seventh day of the experiment and an increase of $25.9 \%$ $(\mathrm{P} \leq 0.05)$ was again registered by the fourteenth day, reaching physiological limits. In calves of the control group, the studied indicator became $2.7 \%$ higher by the seventh day $(\mathrm{P}<0.05)$, and by the fourteenth day it 
increased by $2.2 \%(\mathrm{P} \leq 0.05)$, but did not reach reference values.

Alkaline phosphatase in newborn calves of the experimental group by the seventh day of the experiment decreased by $50.5 \%(\mathrm{P} \leq 0.05)$, while on the fourteenth day there was a further decrease by $58.6 \%(\mathrm{P} \leq 0.05)$, to standard values. In the animals of the control group, a significant decrease in alkaline phosphatase was also noted at the height of the experiment and by the end of completion by $64.5 \%(\mathrm{P} \leq 0.05)$, however, the level was higher than the background values. In the study of cholesterol content, experimental calves demonstrated an increase by $45.8 \%$ by the seventh day $(\mathrm{P} \leq 0.05)$ and by
$47.8 \%$ by the fourteenth day $(\mathrm{P} \leq 0.05)$, reaching physiological limits.

In hypotrophic calves in the control group, the studied indicator by the fourteenth day of the study increased by $69.4 \%(\mathrm{P} \leq 0.05)$, but did not reach those values of physiologically mature calves. The content of triglycerides (TG) in calves of the experimental group increased by $56.0 \%(\mathrm{P} \leq 0.05)$ by the seventh day, and by the fifteenth day of the study it increased by $40.5 \%$ $(\mathrm{P} \leq 0.05)$ and reached reference values.

By the seventh day of the study, this indicator in control animals increased by $31.6 \%(\mathrm{P} \leq 0.05)$ and increased by the fifteenth day by $29.6 \%(\mathrm{P} \leq 0.05)$, but without reaching physiological parameters (see Table 1).

Table 1. Result of the action of complex therapy on hematomorphological and biochemical parameters of calves with comorbid pathologies

\begin{tabular}{|c|c|c|c|}
\hline Indicators & $\begin{array}{l}\text { experimental } \\
(n=6)\end{array}$ & $\begin{array}{c}\text { control } \\
(\mathrm{n}=6)\end{array}$ & $\begin{array}{c}\text { reference values } \\
(\mathrm{n}=6)\end{array}$ \\
\hline Erythrocytes $\left[10^{12} / 1\right]$ & $\begin{array}{c}7.84 \pm 0.98^{*} \\
6.11 \pm 0.19^{* *}\end{array}$ & $\frac{5.0 \pm 0.5}{5.6 \pm 0.6}$ & $\frac{7.77 \pm 0.5}{7.98 \pm 0.18}$ \\
\hline Hemoglobin $[\mathrm{g} / \mathrm{l}]$ & $\frac{135.78 \pm 5.91^{*}}{84.29 \pm 4.92^{* *}}$ & $\frac{90.1 \pm 11.0}{100.0 \pm 4.1}$ & $\frac{131.55 \pm 11.0}{142.63 \pm 7.70}$ \\
\hline Hematocrit [\%] & $\begin{array}{l}41.78 \pm 2.93^{*} \\
33.86 \pm 2.98^{* * *} \\
\end{array}$ & $\begin{array}{l}39.66 \pm 2.93^{*} \\
34.15 \pm 1.99^{* *} \\
\end{array}$ & $\frac{42.65 \pm 2.93}{49.25 \pm 0.03}$ \\
\hline Iron $[\mu \mathrm{mol} / 1]$ & $\begin{array}{c}24.61 \pm 1.98^{*} \\
15.63 \pm 2.87^{* * * *} \\
\end{array}$ & $\begin{array}{c}19.88 \pm 2.00^{*} \\
14.87 \pm 2.55^{* * *}\end{array}$ & $\frac{20.10 \pm 3.88}{23.15 \pm 5.93}$ \\
\hline Copper $[\mu \mathrm{mol} / 1]$ & $\begin{array}{l}13.25 \pm 1.01^{*} \\
9.56 \pm 2.33^{* *}\end{array}$ & $\begin{array}{l}11.32 \pm 1.25^{*} \\
9.78 \pm 2.21^{* *}\end{array}$ & $\frac{14.01 \pm 1.85}{12.65 \pm 4.01}$ \\
\hline $\mathrm{TIBC}[\mu \mathrm{mol} / \mathrm{l}]$ & $\begin{array}{c}75.98 \pm 9.87^{*} \\
88.23 \pm 17.97^{* * *}\end{array}$ & $\begin{array}{c}80.98 \pm 8.77^{*} \\
87.79 \pm 17.00^{* * *}\end{array}$ & $\frac{76.11 \pm 8.01}{71.33 \pm 15.32}$ \\
\hline Leukocytes $\left[10^{9} / 1\right]$ & $\frac{6.4 \pm 1.1^{*}}{6.0 \pm 1.2}$ & $\frac{6.9 \pm 0.8}{7.9 \pm 1.1}$ & $\frac{6.5 \pm 0.2}{4.7 \pm 0.9}$ \\
\hline T-lymphocytes $\left[10^{9} / 1\right]$ & $\frac{1.9 \pm 0.14}{1.10 \pm 0.15}$ & $\frac{1.10 / 0.1 * 1}{1.0 \pm 0.18}$ & $\frac{1.7 \pm 0.18}{1.51 \pm 0.17}$ \\
\hline B-lymphocytes $\left[10^{9} / 1\right]$ & $\frac{0.90 \pm 0.17 *}{0.50 \pm 0.09}$ & $\frac{0.50 \pm 0.14}{0.48 \pm 0.11}$ & $\begin{array}{l}0.89 \pm 0.12 \\
0.69 \pm 0.07\end{array}$ \\
\hline SBA [\%] & $\frac{71.6 \pm 2.1 *}{48.9 \pm 1.3}$ & $\frac{49.6 \pm 1.3}{49.1 \pm 1.4}$ & $\frac{71.5 \pm 1.5}{67.7 \pm 1.3}$ \\
\hline SLA $[\mu \mathrm{g} / \mathrm{ml}]$ & $\frac{0.80 \pm 0.16}{1.30 \pm 0.15}$ & $\frac{0.47 \pm 0.11^{*}}{1.27 \pm 0.13}$ & $\frac{0.82 \pm 0.13}{0.33 \pm 0.12}$ \\
\hline Glucose [mmol/1] & $\begin{array}{l}6.92 \pm 0.42^{*} \\
3.89 \pm 0.35^{* *}\end{array}$ & $\frac{4.71 \pm 0.51}{3.93 \pm 0.27}$ & $\frac{5.04 \pm 058}{5.74 \pm 0.69}$ \\
\hline Phosphorus [mmol/l] & $\frac{2.85 \pm 0.15^{*}}{1.79 \pm 0.11^{* * *}}$ & $\frac{1.89 \pm 0.14}{1.80 \pm 0.13}$ & $\frac{2.94 \pm 0.12}{2.78 \pm 0.14}$ \\
\hline Alkaline phosphatase $[\mathrm{nmol} / \mathrm{s} * 1]$ & $\begin{array}{c}498.98 \pm 49.6^{*} \\
1189.58 \pm 124.6^{* * *}\end{array}$ & $\begin{array}{c}685.72 \pm 58.1^{*} \\
1196.40 \pm 151.8^{* * *}\end{array}$ & $\frac{505.77 \pm 47.8}{943.38 \pm 61.3}$ \\
\hline Cholesterol [mmol/l] & $\begin{array}{c}3.43 \pm 0.65^{*} \\
0.97 \pm 0.05^{* * *}\end{array}$ & $\begin{array}{c}2.95 \pm 0.74^{*} \\
0.90 \pm 0.06^{* * *}\end{array}$ & $\begin{array}{c}3.75 \pm 0.99^{*} \\
1.34 \pm 0.61^{* * *}\end{array}$ \\
\hline Triglycerides [mmol/l] & $\begin{array}{c}0.42 \pm 0.01^{*} \\
0.11 \pm 0.01^{* * *}\end{array}$ & $\begin{array}{c}0.27 \pm 0.04^{*} \\
0.13 \pm 0.03^{\text {*** }}\end{array}$ & $\begin{array}{c}0.49 \pm 0.06^{*} \\
0.31 \pm 0.01^{* * * *}\end{array}$ \\
\hline
\end{tabular}

Note: the numerator stands for the second study period (12-14th day of research), denominator stands for the period before the experiment (1st day of life). ${ }^{*} \mathrm{P} \leq 0,05 ;{ }^{* *} \mathrm{P} \leq 0,02$

\section{Conclusion}

According to the results of our research, we suggest treating anemia as a syndrome of comorbid hypotrophy, pathogenetically related and mutually aggravating. As a result of testing the complex treatment regimen for calves with trans-syndromic diseases in the neonatal period, the functioning of the electron transport chain of mitochondria, as well as the oxygen-transport function of the blood was restored, the imbalance in the activity of the immune system was corrected, the links of the cellular and humoral status were optimized, the main sources of energy used in the body were restored, used for diverse processes of energy metabolism. Thus, the resistance of newborn calves to adverse environmental conditions increased, linear growth and average daily weight gain normalized corresponding to breed conditions. 


\section{References}

1. S.S. Abramov, S.V. Zasinets, Latent iron deficiency anemia in calves Veter. Med. 6, 43-45 (2004)

2. A.G. Shakhov et al., Features of protective systems in calves with malnutrition syndrome and their role in the development of neonatal pathology Veterinarian 2, 27-30 (2013)

3. S.V. Shabunin, Yu.N. Alekhin, A.G. Nezhdanov, Perinatal pathology in cattle as an urgent problem of veterinary medicine Veter. med. 1, 3-10 (2015)

4. F.N. Gilmiyarova et al., Energy-deficient state, the basis of hypotrophy and comorbid pathology in children Labor. Diagn. 2(42), 60-62 (2016)

5. A.G. Shakhov et al., The effect of immunomodulators of synthetic and bacterial origin on the hemomorphological and biochemical status of hypotrophic calves Veter. Med., zootech. and biotechnol. 4, 18-25 (2014)

6. A.V. Golubtsov et al., The effect of low-intensity laser blood irradiation on the hemomorphological and biochemical status of hypotrophic calves Veter. med. 2, 46-52 (2015)

7. A.G. Nezhdanov et al., Intrauterine growth retardation of the embryo and fetus in cows Veter. med. 3, 36-39 (2014)

8. A.G. Shakhov et al., The immune status of calves with different levels of morphofunctional development Bull. of Russ. Agricult. sci. 6, 58-61 (2013)

9. T.A. Kolesnikova et al., Fetal hypotrophy: realities and prospects Reproduct. health. Eastern Europe 5(23), 321-323 (2012)

10. A.N. Kurilenko, V.L. Krupalnik, N.V. Pimenov, Bacterial and viral diseases of young farm animals (KolosS, Moscow, 2006)

11. E. V. Neudakhin, Clinical, metabolic and genetic aspects of malnutrition in young children, $\mathrm{PhD}$ dissertation thesis (Moscow, 1992)

12. D.A. Savrasov, I.V. Lunegova, K.A. Rozhkov, Current position of a phased methodology for the treatment of calf antenatal hypotrophy using taurine Regulatory issues in veter. med. 4, 145-149 (2015)

13. V.V. Dronov et al., Health status of cows and calf hypotrophy Russ. Veter. J. 1, 6-8 (2013)

14. N.P. Shabalov, Deficit states, Children's diseases (Piter, St. Petersburg, 2011)

15. M.A. Ballou, Immune responses of Holstein and Jersey calves during the preweaning and immediate postweaned periods when fed varying planes of milk replacer J. Dairy Sci. 95, 7319-7330 (2012)
16. Z. A. Bhutta, Micronutrient needs of malnourished children Curr. Opin. Clin. Nutr. Metab. Care. 11(3) 309-314 (2008)

17. K. Godfrey, D. Barker, Fetal nutrition and adult disease Am. J. Clin. Nutr. 71(5), 1344-1352 (2000)

18. Zubin Grover, Looi C. Ee, Protein Energy Malnutrition Pediatric Clinics of North America 56(5), 1055-1068 (2009)

19. I. Sermet-Gauelus, A. S. Poisson-Salomon, V. Colomb et al., Simple pediatric nutritional risk score to identify children at risk of malnutrition AJCN 72, 64-70 (2000)

20. A.G. Shakhov, I.V. Cheremushkina, A.E. Chernitskiy, Feed additive for increase of productivity and natural resistance of young agricultural animals Int. J. of Pharm. and Technol. 8(4), 26876-26881 (2016)

21. M. Schoonderwoerd, C.E. Doige, G.A. Wobeser, J.M Naylor, Protein Energy Malnutrition and Fat Mobilization in Neonatal Calves Canad. Veter. J. La revue veter. Canadienne 27(10), 365-371 (1986 Oct.)

22. M.F. Karashaev, The distribution of anemia in calves Bull. of the Russ. Acad. of Agricult. Sci. 1, 89-90 (2007)

23. N.A. Pudovkin, M.N. Panfilova, A.A. Sazonov, Animal anemia, its treatment and prevention: a methodological guide (Format, Saratov, 2012)

24. A.G. Shakhov et al., Guide for the diagnosis and prevention of disorders of antenatal and intranatal origin in calves 26-39 (Istoki, Voronezh, 2013)

25. A.G. Shakhov et al., Guidelines for the assessment and correction of the immune status of animals (Istoki, Voronezh, 2005)

26. R.H. Clark, D.H. Chace, A.R. Spitzer, Impact of Lcarnitine supplementation on metabolic profiles in premature infants J. of Perinatology 37(5), 566-71 (2017) DOI: 10.1038/jp.2016.253

27. H.V. Semlitsch, P. Anderer, B. Saletu et al., Topographic mapping of cognitive event-related potentials in a double-blind, placebo-controlled study with the hemoderivative Actovegin in ageassociated memory impairment Neurophychobiol. 24, 49-56 (1990-1991)

28. S.W. Schaffer, J. Azuma, M. Mozaffari, Role of antioxidant activity of taurine in diabetes Can. J. Physiol. Pharmacol. 87, 91-99 (2009)

29. T. Suzuki, T. Wada, K. Saigo, K. Watanabe, Taurine as a constituent of mitochondrial tRNAs: new insights into the functions of taurine and human mitochondrial diseases Embo. J. 21, 6581-6589 (2002) 